\title{
Pt/C Catalysts for the Oxygen Reduction Reaction: Correlation of Carbon Support Morphology and Catalytic Activity
}

\author{
B. Tesche, H. Schulenburg, B. Spliethoff and M.T. Reetz \\ Max-Planck-Institut für Kohlenforschung, Kaiser-Wilhelm-Platz 1, \\ D-45470 Muelheim an der Ruhr, Germany
}

Carbon supported platinum nanoparticles $(\mathrm{Pt} / \mathrm{C})$ as well as various platinum alloys on carbon constitute commonly used electrocatalysts in polymer electrolyte membrane fuel cells [1]. They catalyse the anodic oxidation of hydrogen a well as the cathodic reduction of oxygen. Irrespective of the catalyst preparation method, Vulcan XC72 is consistently applied as carbon support. In view of the well-known fact that the morphology of the support can influence the activity of the catalyst, it is surprising that no systematic study has been carried out about the correlation between carrier morphology and the electrocatalytic activity. For better understanding of this correlation, we applied electrochemical and high-resolution TEM (HRTEM) studies of Pt/C catalysts with various carbon supports.

$\mathrm{Pt} / \mathrm{C}$ catalysts with different carbon supports are prepared by the Instant-method [2], which involves formation of $\mathrm{PtOx}$ by basic hydrolysis of hexachloroplatinic acid in presence of a carbon support. Platinum oxide is finally reduced to metallic platinum (eq 1).

$$
\mathrm{H}_{2} \mathrm{PtCl}_{6}+\mathrm{C} \stackrel{\mathrm{Li}_{2} \mathrm{CO}_{3} / \mathrm{H}_{2} \mathrm{O}}{\longrightarrow} \mathrm{PtO}_{\mathrm{x}} / \mathrm{C} \stackrel{\text { Reduction }}{\longrightarrow} \mathrm{Pt} / \mathrm{C}
$$

We prepared Pt/C catalysts with seven carbon black supports (Vulcan XC72 (Cabot), ISAF (Columbian Carbon), Corax N234g, N115, N220, EB111, Printex XE2 (all from Degussa)), and two different carbon nanofibers (PL-CNF and SC-CNF (both from Future Carbon)). We achieved remarkably high Pt loadings, namely up to $60 \%$, which is desirable for fuel cell applications. The size of PtOx particles (1-2 nm) is homogeneous on all carbon supports.

After electrochemical reduction of $\mathrm{PtOx} / \mathrm{C}$ to $\mathrm{Pt} / \mathrm{C}$ rotating disc electrode measurements [3] were performed in order to ascertain the catalytic activity for oxygen reduction. The particle size of reduced platinum particles was determined by HRTEM and cyclic voltammetry. We applied heavy metal shadowing [4] to obtain information about the surface structure of the carbon supports. It turned out that during electrochemical reduction of $\mathrm{PtOx} / \mathrm{C}$ to $\mathrm{Pt} / \mathrm{C}$ sintering of $\mathrm{Pt}$ nanoparticles occurs. This undesired process leads to a loss of platinum surface area and therefore a loss of activity.

HRTEM images show that carbon supports with rough surfaces like Printex XE2 (Fig.1) are able to minimize the sintering of Pt nanoparticles. As a consequence Pt/Printex XE2 catalysts show much higher catalytic activity than $\mathrm{Pt} / \mathrm{C}$ catalysts with smoother carbon supports like the commercial Vulcan XC72 (Fig. 2). 
At $0,9 \mathrm{~V}$ (NHE) our Pt/Printex XE2 catalyst shows a 34\% higher catalytic activity than a Pt/Vulcan XC72 catalyst (ETEK) with a similar metal loading [5]. We expect that other carbon blacks having a similar rough surface will also lead to electrocatalysts with such dramatically improved activity.

\section{References}

[1] Handbook of Fuel Cells, Technology and Applications, Edited by W. Vielstich, H.A. Gasteiger, A. Lamm, Vol. 2, John Wiley \& Sons, Ltd. (2003)

[2] M. Lopez, Dissertation, Ruhr-Universitaet Bochum (2002)

[3] T.J. Schmidt, H.A. Gasteiger, G.D. Stäb, P.M. Urban, D.M. Kolb, R.J. Behm, J. Electrochem. Soc. (1998), 145, 2354

[4] B. Tesche, H. Schmiady, Ultramicrosopy 15 (1985), 422-435

[5] M.T. Reetz, H. Schulenburg, M. Lopez, B. Spliethoff, B. Tesche, Chimia (2004), 58, No. 12, 896-899
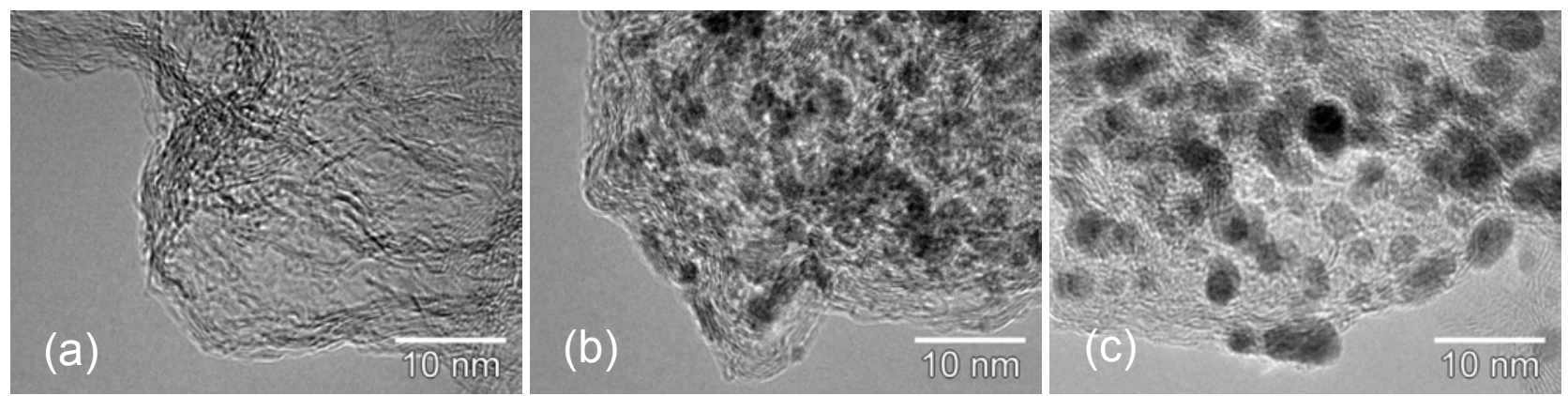

Fig. 1. HRTEM images of Printex XE based materials: Unloaded carbon support (a); PtOxloaded carbon support (b); $\mathrm{Pt} / \mathrm{C}$ following electrocemical reduction (c)
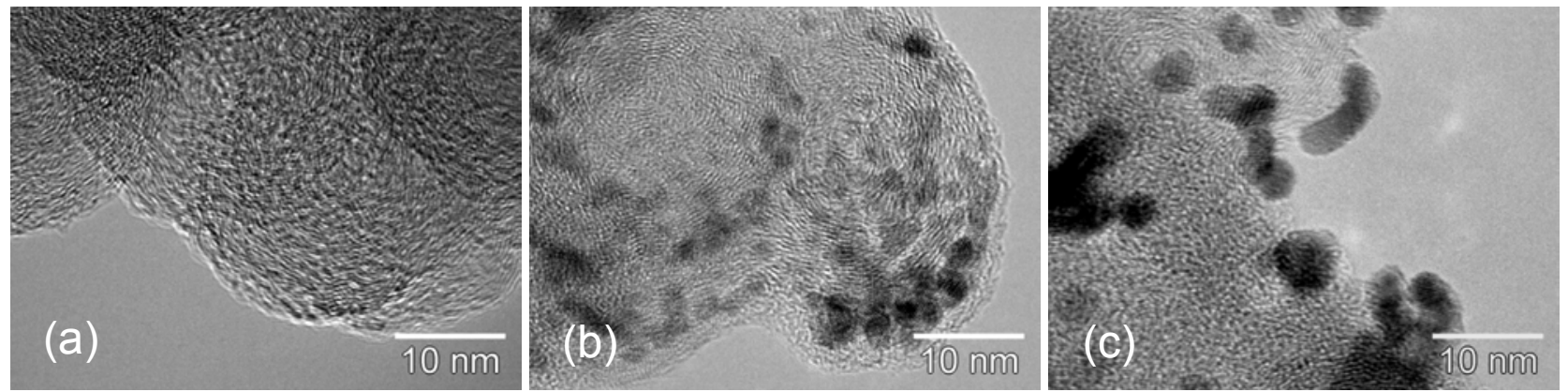

Fig. 2. HRTEM images of Vulcan XC72 based materials: Unloaded carbon support (a); PtOxloaded carbon support (b); Pt/C following electrochemical reduction (c) 